\title{
ENERGY POTENTIAL OF THE FISCHER-TROPSCH FUEL PRODUCED FROM SPRUCE WOOD
}

\author{
Jan Polednik ${ }^{1}$, Jozef Martinka ${ }^{2}$, Peter Rantuch ${ }^{2}$, Karol Balog $^{2}$, Jan Skrinsky ${ }^{1}$, \\ Mateusz Wnukowski ${ }^{3}$, Zdenek Lacny ${ }^{1}$, Ales Bernatik ${ }^{1}$ \\ ${ }^{1}$ Vsb - Technical University of Ostrava \\ Czech Republic \\ ${ }^{2}$ Slovak University of Technology In Bratislava \\ Slovakia \\ 3University of Science and Technology \\ Poland \\ (Received May 2020)
}

\begin{abstract}
The Fischer-Tropsch process is a chemical reaction that enables liquid hydrocarbons to be produced from coal, natural gas, or biomass (e.g. wood). The heat of combustion and effective heat of combustion are important data for fuel used to produce energy. The usefulness of a particular fuel for society is usually evaluated on the basis of the energy returned versus the energy invested $($ EROI $)=$ energy recovered/energy invested. The subject of the research was the product of a Fischer-Tropsch synthesis from a synthesis gas, which was produced through the liquefaction of sawdust from spruce wood. The synthesis took place in the reactor FIX BED at a temperature of 220 to $350^{\circ} \mathrm{C}$ and a pressure of 2 to $3 \mathrm{MPa}$ (the hydrogen to carbon monoxide ratio was approximately 2:1). The Fischer-Tropsch fuel that was produced had a heat of combustion of $27.79 \mathrm{M} \cdot \mathrm{kg}^{-1}$, effective heat of combustion $25.14 \mathrm{M} \cdot \mathrm{kg}^{-1}$ and an EROI coefficient of 2.39 .
\end{abstract}

KEYWORDS: Fischer-Tropsch fuel, spruce wood, EROI, effective heat of combustion, safety.

\section{INTRODUCTION}

The Fischer-Tropsch process or the Fischer-Tropsch synthesis is a chemical reaction converts synthesis gas (a mixture of carbon monoxide and hydrogen) into a mixture of liquid hydrocarbons. According to Peer et al. (2013), in particular, the synthesis gas is made from coal, natural gas, heavy petrochemical fractions, or biomass (e.g. wood). The Fischer-Tropsch process was developed and patented in 1926 by two German scientists, Franz Fischer and Hans 
Tropsch of the Kaiser Wilhelm Institute. In the past, this process was used to produce liquid fuels particularly in countries with limited access to oil (especially Germany and Japan during World War II as well as the Republic of South Africa during apartheid). After World War II, the importance of this process declined due to the relatively low price of oil Peer et al. (2013). Despite the fact that from an economic perspective, the importance of the Fischer-Tropsch process is currently relatively low, scientists have increasingly become interested in this area over the last few decades. The second wave of interest in this field began in the early 1990s, as demonstrated by the scientific works of Ashcroft et al. (1990) and Suslick et al. (1991) that investigated the process of synthesis gas (for Fischer-Tropsch synthesis) production. With respect to the enormous amount of interest shown by scientists in the Fischer-Tropsch synthesis, it is noteworthy to mention the scientific work of Proskurowski et al. (2008) and Torres Galvis et al. (2012) that investigated catalysis of the Fischer-Tropsch synthesis. The increasing level of interest of scientists in this field is the result of the circumstances mentioned: (1) As the oil reserves are depleted, the price of oil will probably continue to increase, and at some point, it will reach a threshold at which the price of fuel made from crude oil will equal the price of liquid fuel produced using the FischerTropsch process. (2) The Fischer-Tropsch process can even be used to produce liquid fuels from bio-renewable sources with net-zero carbon dioxide (CO2) emissions, especially from biomass (e.g. waste wood). Additionally, on 4 November 2016, the Paris Agreement on Climate Change (United Nations 2015) came into force, the main objective of which is to hold the increase in the global average temperature to well below $2^{\circ} \mathrm{C}$ above pre-industrial levels and to pursue efforts to limit the temperature increase to $1.5^{\circ} \mathrm{C}$ above pre-industrial levels. In order to achieve this, it is necessary to replace at least some of the fossil fuels with fuels with net-zero $\mathrm{CO} 2$ emissions (it is anticipated that there will be an increase in the production of biomass fuels using the FischerTropsch process). (3) As the fossil fuel reserves are depleted, it is expected that resources will be extracted even from more remote fields. However, the transport of natural gas and especially coal from more remote fields is a complicated and costly process. In such a case, liquefaction using the Fischer-Tropsch process and the transport of the resultant liquid fuel (to the place of consumption) will be a more viable technical and economical solution.

Combining the Fischer-Tropsch process with wind turbines provides some further interesting possibilities. The amount of electricity produced by a wind turbine is dependent on the weather (the intensity and speed of wind) and is relatively hard to regulate. Although it is possible to detach wind turbines when there is excessive wind energy, in the opposite case, with a lack of energy and insufficient wind intensity, wind turbines cannot be regulated. Combining wind turbines with the Fischer-Tropsch process enables the production of liquid fuel when there is an excess of electrical energy, and subsequently when there is a lack of wind turbine energy to produce the shortfall by burning the liquid fuels (produced when there was an excess of energy). The advantage of producing electrical energy from liquid fuels (as opposed to direct production through burning biomass) is the simplified control and regulation of the process of producing electrical energy. The main reason is that the power of burner for liquid fuel can be immediately controlled (by flow rate of fuel). On the other hand the power of boiler for solid fuel can also be controlled rapidly (by airflow to boiler control) but not as immediately as burner for liquid fuel. The other reason is that according to Ladomersky and Hroncova (2003) the change of boiler power for solid fuel can be cause up to 50 times higher carbon monoxide emission in the first seconds after boiler power change (this increase of carbon monoxide emission has not been observed for boiler for liquid fuels).

The underlying basis of the Fischer-Tropsch process are the chemical reactions expressed by Eqs. 1 to 3 as given, for instance, in De Klerk (2013). 


$$
\begin{aligned}
& n \mathrm{CO}+2(n+\xi) \mathrm{H}_{2} \rightarrow \mathrm{C}_{\mathrm{n}} \mathrm{H}_{2(\mathrm{n}+\xi)}+n \mathrm{H}_{2} \mathrm{O}, \xi=0 \text { or } 1 \\
& n \mathrm{CO}+2(n-\xi) \mathrm{H}_{2} \rightarrow \mathrm{C}_{n} \mathrm{H}_{2(\mathrm{n}+1-\xi)} \mathrm{O}+(n-1) \mathrm{H}_{2} \mathrm{O}, \xi=0 \text { or } 1 \\
& n \mathrm{CO}+2(n-1) \mathrm{H}_{2} \rightarrow \mathrm{C}_{\mathrm{n}} \mathrm{H}_{2 \mathrm{n}} \mathrm{O}_{2}+(n-1) \mathrm{H}_{2} \mathrm{O}
\end{aligned}
$$

The Fischer-Tropsch synthesis is primarily a hydrocarbon synthesis, with typically more than $85 \%$ of the carbon-containing product being hydrocarbons (mainly alkanes, alkenes and cycloalkanes) De Klerk (2013). In practice, products of the Fischer-Tropsch process are either used directly as liquid fuels (they may be modified prior to use) or their individual components (chemical substances) may be separated through distillation.

The following three parameters are important for the characterization of liquid products of the Fischer-Tropsch synthesis: The Heat of Combustion (HC), Effective Heat of Combustion (EHC) and Energy Return on Investment (EROI). EROI is defined as the ratio of energy recovered divided by energy invested. The higher the EROI, the more useful the fuel is for society from an energy perspective. In order for the fuel to be useful, its EROI must be at least 5 to 7 (Mearns 2016). Less demanding requirements (an EROI of at least 3) for fuel to be considered useful has been reported by Hall et al. (2014). The facts stated above show that the requirements and recommendations of the scientific community and experts significantly differ in terms of the minimum acceptable EROI value (they often range from 3 to 7 ). These differences are mostly the result of developments over time (as the EROI of most energy sources decreases, e.g. due to the greater remoteness of the sources). Considering the continuous effort to limit global warming, it may be assumed that in the future, fuels with net-zero $\mathrm{CO} 2$ emission will be considered useful by experts and scientists, if they have an EROI of at least 3. The EROI values of common sources of energy are shown in Tab. 1.

Tab. 1: Energy return on energy investment for selected fuels and sources.

\begin{tabular}{|l|c|l|}
\hline \multicolumn{1}{|c|}{ Fuel or resource } & EROI & \multicolumn{1}{c|}{ References } \\
\hline $\begin{array}{l}\text { Coal (between 1950 to 2010) in } \\
\text { US and China }\end{array}$ & $56 \pm 25$ & $\begin{array}{l}\text { Cleveland et al. 1984, Hall et al. 2009, Murphy et al. } \\
\text { 2010, Murphy et al. 2011, Hu et al. 2013, Lambert et al. } \\
\text { 2013, Hall et al. 2014 }\end{array}$ \\
\hline $\begin{array}{l}\text { Oil and gas (between 21970 to } \\
\text { 2010) in Global, US, Canada, } \\
\text { Norway, Mexico and China }\end{array}$ & $23 \pm 16$ & $\begin{array}{l}\text { Cleveland et al. 1984, Hall et al. 1986, Gagnon et al. } \\
\text { 2009, Murphy et al. 2010, Freise 2011, Grandell 2011, } \\
\text { Guilford et al. 2011, Murphy et al. 2011, Hu et al. 2013, } \\
\text { Poisson 2013, Hall et al. 2014 }\end{array}$ \\
\hline Hydropower & $>100$ & $\begin{array}{l}\text { Cleveland et al. 1984, Murphy et al. 2010, Murphy et al. } \\
\text { 2011, Hall et al. 2014 }\end{array}$ \\
\hline Wind turbine & 18 & $\begin{array}{l}\text { Kubiszewski et al. 2010, Murphy et al. 2010, Murphy et } \\
\text { al. 2011, Hall et al. 2014 }\end{array}$ \\
\hline Photovoltaic & 6 to 12 & $\begin{array}{l}\text { Battisti 2005, Murphy et al. 2010, Murphy et al. 2011, } \\
\text { Hall et al. 2014, Kubiszewski et al. 2019 }\end{array}$ \\
\hline Ethanol & 0.8 to 10 & $\begin{array}{l}\text { Hall et al. 1986, Farrell et al. 2006, Goldemberg 2007, } \\
\text { Murphy et al. 2010, Murphy et al. 2011, Hall et al. 2014 }\end{array}$ \\
\hline
\end{tabular}

In spite of this there have only been few scientific studies that have investigated the energy potential (heat of combustion, effective heat of combustion and energy returned on energy invested) of products of the Fischer-Tropsch synthesis produced using synthesis gas (a mixture 
of hydrogen and carbon monoxide) obtained from biomass (wood from coniferous trees). Spruce wood is one the most important wood species in Central and Northern Europe (therefore a lot of spruce wood dust is generated in the wood industry). Nevertheless no scientific work investigated energy potential and EROI coefficient of the Fischer-Tropsch fuel produced from spruce wood have been published yet.

Hence, the aim of this study is to identify the energy potential and energy return on energy investment of chosen Fischer-Tropsch fuel produced from synthesis gas obtained from the Norway spruce (Picea abies (L.) Karst.).

\section{MATERIAL AND METHODS}

The Fischer-Tropsch fuel examined was made of synthesis gas. The synthesis gas was obtained from the Norway spruce (Picea abies (L.) Karst.). The density of investigated dry (dried at constant mass at $103 \pm 2^{\circ} \mathrm{C}$ ) spruce wood was $397 \pm 17 \mathrm{~kg} \cdot \mathrm{m}^{-2}$. Other basic characteristics of the investigated spruce wood used to produce the synthesis gas are shown in Tab. 2.

Tab. 2: Characteristics of the raw material used to produce the synthesis gas.

\begin{tabular}{|l|c|}
\hline \multicolumn{1}{|c|}{ Characteristic } & Value \\
\hline Heat of combustion $\left(\mathrm{M} \cdot \mathrm{kg}^{-1}\right)$ & 18.86 \\
\hline Water content (mass \%) & 7 \\
\hline Ash (mass \%) & 0.7 \\
\hline Volatile flammable matter (mass \%) & 77.2 \\
\hline Fixed carbon (mass \%) & 22.1 \\
\hline Carbon (mass \%) & 47.87 \\
\hline Hydrogen (mass \%) & 6.41 \\
\hline Oxygen (mass \%) & 45.61 \\
\hline Nitrogen (mass \%) & 0.1 \\
\hline Sulphur (mass \%) & 0.01 \\
\hline
\end{tabular}

The synthesis gas was produced from the sawdust (raw material) through gasification. The gasifier TEMEX produced and supplied by the TEMEX, s.r.o. (Ostrava, Czech Republic) was used. Temperature and pressure during gasification were 850 to $950^{\circ} \mathrm{C}$ and $100 \pm 1 \mathrm{kPa}$, respectively. The gasification duration was $2 \mathrm{~h}$.

The Fischer-Tropsch fuel was produced using a FIX BED reactor (Vinci Technologies SA, Nanterre, France) with a volume of $0.000141 \mathrm{~m}^{3}$, located at the VSB - Technical University of Ostrava, Czech Republic. The synthesis took place at a temperature of 220 to $350^{\circ} \mathrm{C}$ and a pressure of 2 to $3 \mathrm{MPa}$ over the course of 4 hours. The ratio of hydrogen to carbon monoxide in the synthesis gas was approximately $2: 1$.

The heat of combustion and effective heat of combustion were determined using an oxygen bomb calorimeter (IKA C4000, Staufen im Breisgau, Germany). The calorimeter and the test method used are compliant with ISO 1716 (2018). The final value of the heat of combustion and effective heat of combustion has been computed as arithmetic average of three measured values \pm standard deviation (the number of measured samples have been 3 ).

The chemical composition of the Fischer-Tropsch fuel produced was determined by chromatograph analysis. The chromatograph analysis has been done by the GCMSD 5977 
gas chromatograph (produced and supplied by Agilent Technologies, Inc., Santa Clara, United States). Chromatograph detector type: UV/VIS, column type and length: Stabilwax-DA $30 \mathrm{~m}$, carrier gas: helium.

\section{RESULTS AND DISCUSSION}

The chromatogram of the Fischer-Tropsch fuel under investigation is shown in Fig. 1. The chromatogram (Fig. 1) shows that the Fischer-Tropsch fuel was predominantly composed of the chemical substances listed in Tab. 3 (the cited table includes the boiling temperatures of these chemical substances).

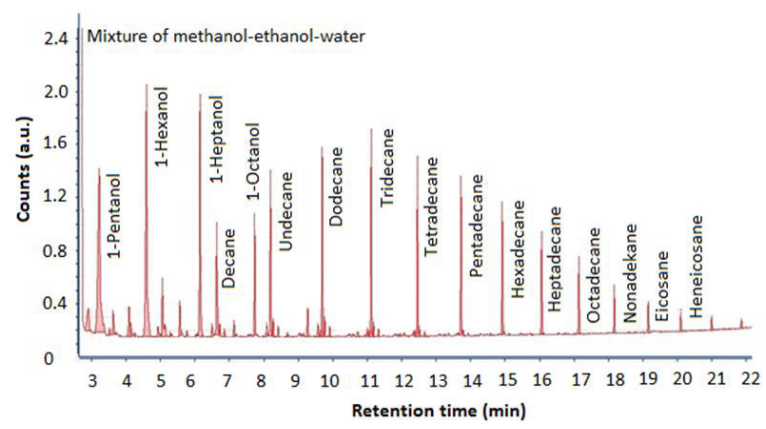

Fig. 1: Chromatogram of the Fischer-Tropsch fuel investigated.

Tab. 3: Main components of the Fischer-Tropsch fuel investigated.

\begin{tabular}{|l|c|}
\hline \multicolumn{1}{|c|}{ Chemical substance } & Boiling temperature $\left({ }^{\circ} \mathbf{C}\right)$ \\
\hline Methanol & 64.7 \\
\hline Ethanol & 78.37 \\
\hline Water & 100 \\
\hline 1-Pentanol & 138 \\
\hline 1-Hexanol & 155.8 \\
\hline 1-Heptanol & 175.8 \\
\hline Decane & 174.1 \\
\hline 1-Octanol & 195 \\
\hline Undecane & 196 \\
\hline Tridecane & 234 \\
\hline Tetradecane & 253.6 \\
\hline Pentadecane & 271 \\
\hline Hexadecane & 286.8 \\
\hline Heptadecane & 302 \\
\hline Octadecane & 317 \\
\hline Nonadekane & 330 \\
\hline Eicosane & 343.9 \\
\hline Heneicosane & 356 \\
\hline
\end{tabular}

Source of boiling temperatures: Haynes (2015). 
The heat of combustion and effective heat of combustion of the fuel examined is shown in Tab. 4. The comparison of the results in Tab. 4 with the results of other scientific studies (Karlsson and Quintiere 1999, Gunther et al. 2012, Akaki et al. 2012, Todaro et al. 2015, Carosio et al. 2016) proves that the Fischer-Tropsch fuel examined has a higher heat of combustion and effective heat of combustion than wood, wood-based materials and biomass, yet a lower heat of combustion and effective heat of combustion than most plastics, coal and coke. The heat of combustion and effective heat of combustion of the fuel (Tab. 4) lies between the heat of combustion and the effective heat of combustion of methanol - heat of combustion $22.8 \mathrm{M} \cdot \mathrm{kg}^{-1}$ and effective heat of combustion $19.9 \mathrm{M} \cdot \mathrm{kg}^{-1}$ according to (Haynes 2015) and ethanol heat of combustion $29.7 \mathrm{M} \cdot \mathrm{kg}^{-1}$ and effective heat of combustion $26.7 \mathrm{M} \cdot \mathrm{kg}^{-1}$ according to (Haynes 2015). This conclusion is in accordance with Fig. 1, according to which the mixture investigated is mainly composed of methanol and ethanol. The comparative analysis of Tab. 2 and Tab. 4 reveals that the Fischer-Tropsch fuel produced has higher heat of combustion (energy density) than the original raw material.

Tab. 4: Heat of combustion and effective heat of combustion of the Fischer-Tropsch fuel investigated.

\begin{tabular}{|c|c|}
\hline Heat of combustion $\left(\mathbf{M} \cdot \mathbf{k g}^{-1}\right)$ & Effective heat of combustion $\left.\mathbf{( M} \cdot \mathbf{k g}^{-\mathbf{1}}\right)$ \\
\hline $27.79 \pm 0.09$ & $25.14 \pm 0.09$ \\
\hline
\end{tabular}

In addition to the heat of combustion and the effective heat of combustion, another important parameter of a fuel is its EROI coefficient. In order to calculate the EROI it is necessary to know more parameters than just the effective heat of combustion. It is crucial to know the EROI of the raw material (biomass), the heat of gasification of the raw material (biomass) and the energy necessary for the synthesis of the Fischer-Tropsch fuel from the synthesis gas. According to Pergher (2013), the EROI coefficient of firewood equals 10 and its average effective heat of combustion, according to Gunther et al. (2012), is $17.6 \mathrm{M} \cdot \mathrm{kg}^{-1}$. From above-cited data (EROI and effective heat for combustion of firewood) it is obvious that to get $1 \mathrm{~kg}$ of wood, it is necessary to invest $(17.6 / 10)=1.76 \mathrm{MJ}$ of energy. As Tab. 2 indicates, the amount of volatile combustible matter in wood is $77.2 \%$, thus in order to obtain $1 \mathrm{~kg}$ of synthesis gas (volatile combustible matter), it is necessary to invest $(1.76 / 0.772)=2.28 \mathrm{MJ}$ of heat. According to Simon et al. (2006) and Quintiere (1998), the heat of gasification of wood and wood-based materials is 4 to $6.5 \mathrm{M} \cdot \mathrm{kg}^{-1}$. In further calculations, an average value of $5.25 \mathrm{M} \cdot \mathrm{kg}^{-1}$ will be used. Approximately $3 \mathrm{MJ}$ of heat was required for the synthesis of $1 \mathrm{~kg}$ of the Fischer-Tropsch fuel in the FIX BED reactor. Thus, in order to obtain $1 \mathrm{~kg}$ of the Fischer-Tropsch fuel, it is necessary to invest $(2.28+5.25+3)=$ 10.53 MJ of heat. The EROI coefficient of the Fischer-Tropsch fuel obtained can be calculated as the effective heat of combustion divided by the energy necessary to obtain $1 \mathrm{~kg}$ of this fuel, thus $\mathrm{EROI}=25.14 / 10.53=2.39$. The indicated value is lower than the minimum EROI value of 3 recommended by Hall et al. (2014) as a criterion for useful fuels. However, since the FischerTropsch fuel produced from biomass is a fuel with-net zero $\mathrm{CO}_{2}$ emissions, we assume that even fuels with an EROI lower than 3 will be used in the future (especially in response to efforts to slow or stop global warming).

\section{CONCLUSIONS}

In the presented work the energy potential and EROI coefficient of Fischer-Tropsch fuel produced from synthesis gas obtained from the spruce wood were identified. The chromatographic 
analysis showed that Fischer-Tropsch fuel made from spruce wood is especially composed of a mixture of methanol, ethanol and water, with significant amounts of other alcohols and alkanes. The heat of combustion and effective heat of combustion of the fuel investigated was $27.79 \pm$ $0.09 \mathrm{M} \cdot \mathrm{kg}^{-1}$ and $25.14 \pm 0.09 \mathrm{M} \cdot \mathrm{kg}^{-1}$ respectively. This value is higher than the heat of combustion and the effective heat of combustion of the raw biomass - spruce wood (from which the FischerTropsch fuel was synthesised) and lies between the values of heat of combustion and effective heat of combustion of methanol and ethanol. The EROI coefficient of the investigated FischerTropsch fuel is 2.39. This value is currently too low for direct use as fuel. However, increasing efforts to decelerate or stop global warming may lead to a situation where fuels with net zero $\mathrm{CO}_{2}$ emissions will be considered useful even if they have an EROI of less than 3 .

\section{ACKNOWLEDGEMENTS}

This work was supported by the Slovak Research and Development Agency under the contract No. APVV-16-0223. This work also supported by VSB - Technical University of Ostrava, Faculty of Safety Engineering under the contract No. SP2019/98.

\section{REFERENCES}

1. Akaki, T., Maehara, H., Tooyama, M., 2012: Development of wood and wood ash-based hydroxyapatite composites and their fire-retarding properties. Journal of Wood Science 58(1): 532-537.

2. Ashcroft, A.T., Cheetham, A.K., Foord, J.S., Green, M.L.H., Grey, C.P., Murrell, A.J., Vernon, P.D.F, 1990: Selective oxidation of methane to synthesis gas using transition metal catalysts. Nature 344(1): 319-321.

3. Battisti, R., Corrado, A., 2005: Evaluation of technical improvements of photovoltaic systems through life cycle assessment methodology. Energy 30(1): 952-967.

4. Carosio, F., Cuttica, F., Medina, L., Berglund, L.A., 2016: Clay nanopaper as multifunctional brick and mortar fire protection coating-wood case study. Materials Design 93(1): 357-363.

5. Cleveland, C.J., Costanza, R., Hall, C.A., Kaufmann, R., 1984: Energy and the US economy: a biophysical perspective. Science 225(1): 890-897.

6. De Klerk, A., 2013: Fischer-Tropsch process. In: Kirk-Othmer encyclopedia of chemical technology (ed. Owen M.J.). Wiley, New York, Pp 1-36.

7. Farrell, A.E., Pelvin, R.J., Turner, B.T., Jones, A.D., O'Hare, M., Kammen, D.M., 2006: Ethanol can contribute to energy and environmental goals. Science 311(1): 506-508.

8. Freise, J., 2011: The EROI of conventional Canadian natural gas production. Sustainability 3(1): 2080-2104.

9. Gagnon, N., Hall, C.A.S., Brinker, L., 2009: A preliminary investigation of energy return on energy investment for global oil and gas production. Energies 2(1): 490-503.

10. Goldemberg, J., 2007: Ethanol for a sustainable energy future. Science 315(1): 808-810.

11. Grandell, L., Hall, C.A.S., Höök, M., 2011: Energy return on investment for Norwegian oil and gas from 1991 to 2008. Sustainability 3(1): 2050-2070.

12. Guilford, M.C., Hall, A.C.S., O'Connor, P., Cleveland, C.J., 2011: A new long term assessment of energy return on investment (EROI) for US oil and gas discovery and production. Sustainability 3(1): 1866-1887. 
13. Gunther, B., Gebauer, K., Barkowski, R., Rosenthal, M., Bues, C.T., 2012: Calorific value of selected wood species and wood products. European Journal of Wood and Wood Products 70(1): 755-757.

14. Hall, C.A.S., Balogh, S., Murphy, D.J.R., 2009: What is the minimum EROI that a sustainable society must have. Energies 2(1): 25-47.

15. Hall, C.A.S., Cleveland, C.J., Kaufmann, R. 1986: Energy and resource quality: the ecology of the economic process. Wiley, New York, 577 pp.

16. Hall, C.A.S., Lambert, J.G., Balogh, S.B., 2014: EROI of different fuels and the implications for society. Energy Policy 64(1): 141-152.

17. Haynes, W.M., 2015. Handbook of chemistry and physics. 96th ed. CRC Press. Boca Raton, $2677 \mathrm{pp}$.

18. Hu, Y., Hall, C.A.S., Wang, J., Feng, L., Poisson, A., 2013: Energy return on investment (EROI) of China's conventional fossil fuels: historical and future trends. Energy 54(1): 352-364.

19. ISO 1716, 2018: Reaction to fire tests for products: Determination of the gross heat of combustion (calorific value).

20. Karlsson, B., Quintiere, J., 1999: Enclosure fire dynamics. CRC Press, Boca Raton, 336 pp.

21. Kubiszewski, I., Cleveland, C.J., Endres, P.K., 2010: Meta-analysis of net energy return for wind power systems. Renewable Energy 35(1): 218-225.

22. Kubiszewski, I., Cleveland, C., Szostak, R., 2019: Energy return on investment (EROI) for photovoltaic energy. In: The encyclopedia of Earth. Eol. New York, 4 pp.

23. Ladomersky, J., Hroncova, E., 2003: Monitoring the suitability of burning conditions for wood waste in the combustion chamber based on emissions. In: Acta Mechanica Slovaca 7(3): 595-600.

24. Lambert, J.G., Hall, C.A.S., Balogh, S., Gupta, A., Arnold, M., Poisson, A. 2013: EROI of global energy resources. SUNY - ESF. New York, 160 pp.

25. Mearns, E., 2016: ERoEI for Beginners. Energy Matters 27(1): 19-25.

26. Murphy, D.J., Hall, C.A.S., 2010: Year in review-EROI or energy return on (energy) invested. Annals of the New York Academy of Science 1185(1): 102-118.

27. Murphy, D.J., Hall, C.A.S., Dale, M., Cleveland, C., 2011: Order from chaos: a preliminary protocol for determining the EROI of fuels. Sustainability 3(1): 1888-1907.

28. Peer, V., Najser, J., Chlond, R., 2013: Synthesis of liquid fuels. In: Conference Proceedings of the 14th Energy from Biomasses Conference 2013. Brno University of Technology, Brno, Pp 64-68.

29. Pergher, G., 2013: Technology-analysis: biomass energy - introduction to a technology analysis. Universita degli Studi di Udine. Udine, 14 pp.

30. Poisson, A., Hall, C.A.S., 2013. Time series EROI for Canadian oil and gas. Energies 6(1): 5940-5959.

31. Proskurowski, G., Lilley, M.D., Seewald, J.S., Früh-Green, G.L., Olson, E.J., Lupton, J.E., Sylva, S.P., Kelley, D.S. 2008: Abiogenic hydrocarbon production at lost city hydrothermal field. Science 319(1): 604-607.

32. Quintiere, J.G., 1998 Principals of fire behavior. Delmar Publishers, London, 258 pp.

33. Simon, F.G., Jann, O., Wickstrom, U., Geburting, A., Trubiroha, P., Wachtendorf, V., 2006: Material-environment interactions. In: Springer Handbook of Materials Measurement Methods (ed. Czichos H, Saito T, Smith L). Springer, New York, Pp 789-829.

34. Suslick, K.S., Choe, S.B., Cichowlas, A.A., Grinstaff, M.W., 1991: Sonochemical synthesis of amorphous iron. Nature 353(1): 414-416. 
35. Todaro, L., Rita, A., Cetera, P., D’Auria, M., 2015: Thermal treatment modifies the calorific value and ash content in some wood species. Fuel 140(1): 1-3.

36. Torres, H.M.G., Bitter, J.H., Khare, C.B., Ruitenbeek, M., Dugulan, A.I., De Jong, K.P., 2012: Supported iron nanoparticles as catalysts for sustainable production of lower olefins. Science 335(1): 835-838.

37. United Nations. 2015: Paris Agreement on Climate Change. United Nations, New York, $27 \mathrm{pp}$.

\author{
Jan Polednik, Ales Bernatik \\ Vsb - Technical University of Ostrava \\ Faculty of Safety Engineering \\ Lumirova 630/13 \\ 700 30 Ostrava - Vyskovice \\ Czech Republic
}

*Jozef Martinka, Peter Rantuch, Karol Balog

Slovak University of Technology in Bratislava

Faculty of Materials Science and Technology in Trnava

Jana BotTu 278I/25

9I7 24 Trnava

Slovakia

*Corresponding author: jozef.martinka@stuba.sk

Jan Skrinsky, Zdenek Lacny

Vsb - Technical University of Ostrava

Energy Research Centre

i7. Listopadu i5/2172, 70833 Ostrava

Czech Republic

Mateusz Wnukowski

University of Science and Technology

Faculty of Mechanical and Power Engineering

Wybrzeże WyspiańsKiego

27, 50-370 WrocŁaW

POLAND 
